\title{
Testosterone secretion, musth behaviour and social dominance in captive male Asian elephants living near the equator
}

\author{
G. A. Lincoln ${ }^{1}$ and W. D. Ratnasooriya ${ }^{2}$ \\ ${ }^{1}$ MRC Reproductive Biology Unit, Centre for Reproductive Biology, 37 Chalmers Street, \\ Edinburgh EH3 9EW, UK; and ${ }^{2}$ Department of Zoology University of Colombo, PO Box 1490, \\ Colombo 3, Sri Lanka
}

\begin{abstract}
Testosterone concentrations were measured in blood samples collected weekly over a 5 year period from six adult (19-40 year old) male Asian elephants (Elephas maximus maximus) living in captivity in Sri Lanka $\left(7^{\circ} \mathrm{N}\right)$, to investigate the relationship between androgen secretion and the occurrence of musth (temporal gland secretion, drip urination and aggressive behaviour). The testosterone profiles were very variable both within and between animals. Long-term phasic changes in blood concentrations of testosterone, associated with periods of musth, occurred in three of the six elephants, with the most pronounced cyclicity in the oldest animal. Musth occurred annually after periods of high androgen secretion and there was a positive correlation between the duration of musth and mean concentrations of testosterone during the previous 2 months. The time of musth, while consistent for an individual, was variable between animals. In four bulls living within one social group, there was a positive correlation between social rank and mean concentrations of testosterone over the 5 year study, and only the dominant animal showed periodic musth. Short-term changes in testosterone concentrations occurred in blood samples collected every $15 \mathrm{~min}$ for $7 \mathrm{~h}$, and following the injection of $20 \mu \mathrm{g} \mathrm{GnRH}$, consistent with regulation through the pulsatile secretion of LH. Overall, the results support the view that fully mature male Asian elephants living near the equator express an asynchronous, cyclical, circannual pattern of gonadal activity, with the cyclical pattern developing progressively from 20 to 40 years of age. The periodic increase in testosterone secretion during the gonadal cycle induces the development of musth; however, androgen withdrawal following a period of hypersecretion may be the cause of some aspects of musth behaviour (aggression, unpredictability, disobedience) which make bull elephants very difficult to manage in captivity.
\end{abstract}

\section{Introduction}

The phenomenon of musth is best documented in captive male Asian elephants (Elephas maximus) but also occurs in male African elephants (Loxodonta africana), and is a natural feature of the life cycle in the wild for both species (McCaughey, 1963; Poole and Moss, 1981; Poole, 1994). Musth appears to be similar to rutting behaviour in ungulates (Poole, 1987) and is associated with periodic increases in testosterone secretion (Jainudeen et al., 1972a; Hall-Martin and van der Walt, 1984; Cooper et al., 1990; Niemuller and Liptrap, 1991). During musth, males spend less time feeding, leave the bachelor herd, wander long distances in search of females in oestrus, become aggressive towards other males, vocalise with infrasound, produce copious secretions from the enlarged temporal glands and drip urine from the prepuce. Most matings are achieved during this phase (Hall-Martin, 1987; Poole, 1989). The older bulls usually come into musth annually at a specific time of

Received 8 March 1996. year; however, there is no synchrony between individuals in the population, and there may be males in musth at all times of the year (Poole, 1994). In captivity, male Asian elephants in musth can be very dangerous and unmanageable, and are usually kept restrained with chains away from contact with people (Eisenberg et al., 1971).

There have been only a few longitudinal studies that document the long-term changes in testosterone secretion associated with musth in male elephants. For practical reasons, these have involved animals living in captivity at latitudes well outside the normal range for the species (for example, Asian and African elephants in Columbus Zoo, Powel, Ohio, USA at $50^{\circ} \mathrm{N}$, Cooper et al., 1990; Asian elephants in captivity in Ontario, Canada at $54^{\circ} \mathrm{N}$; Niemuller and Liptrap, 1991). Thus, the purpose of the current study was to assess the pattern of cyclicity under equatorial conditions by documenting the changes in blood concentrations of testosterone and behaviour over 5 years in male Asian elephants living in captivity in Sri Lanka. This was a collaborative study between the National Zoological Gardens based in Colombo, the Department of 
Zoology, University of Colombo, Sri Lanka, and the Universities Federation for Animal Welfare (UFAW) based in London, with the overall objective of developing more humane ways of managing male elephants in musth and of improving the success of breeding Asian elephants in captivity (Poole et al., in press).

\section{Materials and Methods}

\section{Animals and sampling}

Six adult, male Asian elephants of the Sri Lankan subspecies (Elephas maximus maximus) were used in the study which was conducted from 1986 to 1991. The animals were cared for individually by mahouts and lived in two different social environments (see Fig. 1). Two males, E11M (Bandula, 40 years in 1986) and E12 (Sampath, 20 years) were housed within the National Zoological Gardens in Colombo, Sri Lanka $\left(6^{\circ} 54^{\prime} \mathrm{N}\right.$, $79^{\circ} 52^{\prime} \mathrm{E}$ ). They were normally kept tethered in an open building alongside females, but were paraded for the public and bathed twice a day. Food, consisting of trunks and branches of Caryota arena, leaves and woody parts of Artocarpus heterophyllus and Cocos nucifera, was provided in the evening. The other four elephants, E3M (Wijaya, 22 years), E4M (Kadira, 19 years), E5M (Jandura, 19 years) and E6M (Neela, 20 years) lived in the Pinnawala Elephant Orphanage about 50 miles north of Colombo. The animals were also tethered overnight, but during the day they were released into a 12 hectare coconut plantation to feed along with a group of six adult female and at least twenty young elephants (Fig. 1). Supplementary food consisted of approximately $76 \mathrm{~kg}$ foliage at night and $2 \mathrm{~kg}$ food mixture (maize meal, rice bran, powdered ginger seed and minerals) in the middle of the day. All the animals at the Orphanage were walked approximately $1 \mathrm{~km}$ in the morning and evening to bath in a shallow river. The ages of the five younger animals were known accurately as they were taken from the wild as juveniles, or born in captivity. The age of the older elephant was estimated by the experienced mahout based on body size and tooth eruption. All animals were of adult body size (Fig. 1) but the exact height and weight were not determined.

Blood samples were collected at $09.00-10.00 \mathrm{~h}$ at weekly intervals by the staff of the National Zoological Gardens. The procedure involved the mahout instructing the elephant to lie down to permit a blood sample $(5-10 \mathrm{ml})$ to be withdrawn from a vein on the back of the ear. The animals were habituated to the sampling and were normally compliant even during periods of musth, thus no special techniques were used to restrain the animals which might have influenced the patterns of hormone secretion. The blood was allowed to clot for $\mathrm{I}-2 \mathrm{~h}$ at room temperature $\left(28-31^{\circ} \mathrm{C}\right)$ before centrifugation at $3000 \mathrm{rpm}$ for $15 \mathrm{~min}$, and the serum was stored at $-20^{\circ} \mathrm{C}$. On one occasion, blood samples were collected at 15 min intervals for $9 \mathrm{~h}$ from two of the elephants (E4M and $\mathrm{E} 6 \mathrm{M}$ ) to monitor short-term fluctuations in testosterone secretion, and at $15 \mathrm{~min}$ intervals for $2 \mathrm{~h}$ from all six elephants to monitor the response to a standardised injection of $\mathrm{GnRH}(20 \mu \mathrm{g} \mathrm{GnRH}$ per elephant i.v., Cambridge Research Biochemical, Northwich). For this, the elephants were walked alongside a raised platform, and blood samples were collected by venepuncture from a vein on the
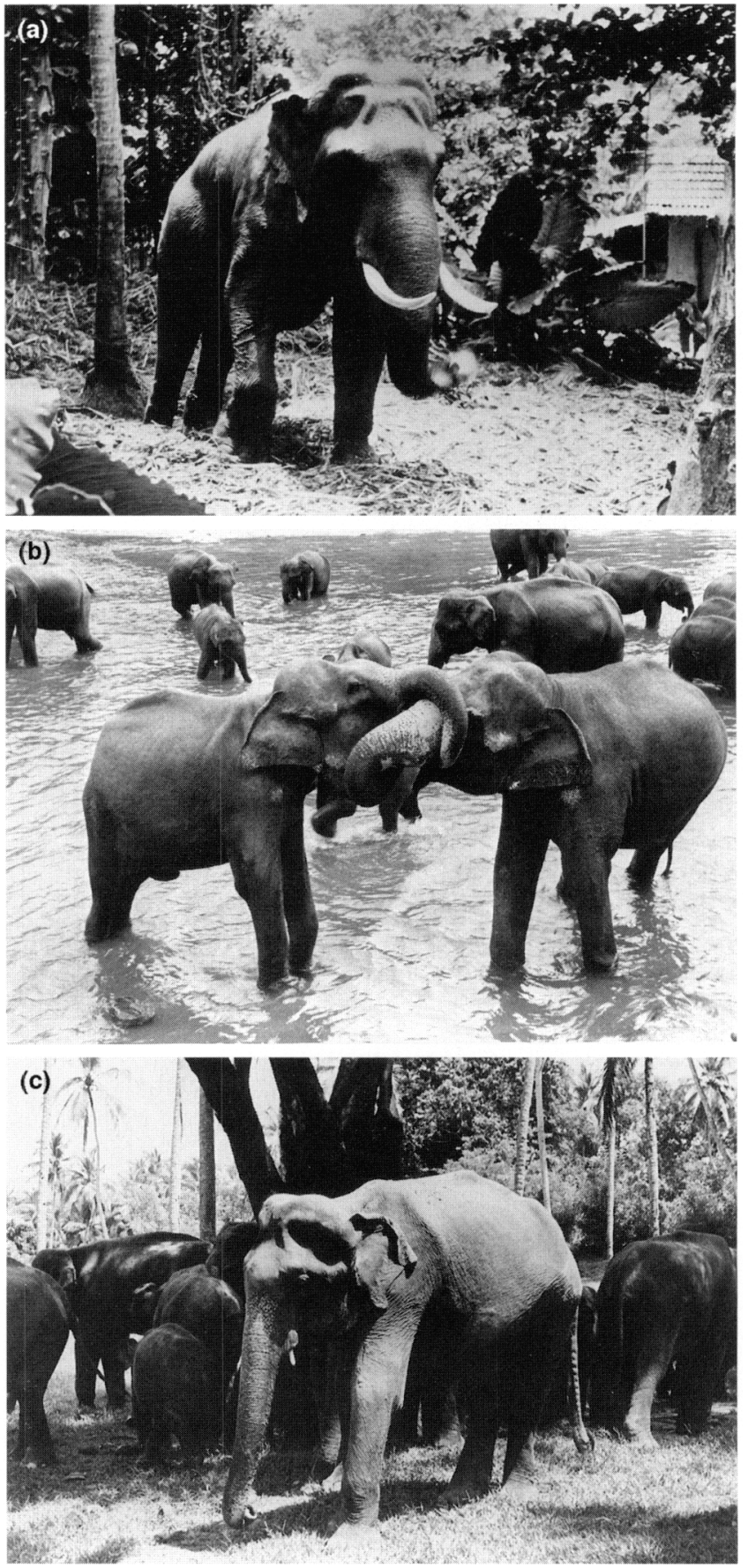

Fig. 1. (a) E12M (Sampath, 24 years old) in National Zoological Gardens, Colombo, Sri Lanka showing musth in July 1990 associated with high blood concentrations of testosterone, see Fig. 2. $\mathrm{He}$ was chained to a tree because of his increased aggressiveness. (b) Dominant elephant E3M (Wijaya, 26 years old, right) in the Pinnawala Elephant Orphanage, Sri Lanka showing social interaction with the next most dominant bull E6M (Neela, 24 years, left) in May 199I. (c) E4M (Kadira, 23 years old) showing the daytime behaviour in the coconut plantation in Pinnawala Elephant Orphanage with close proximity between elephants. Note the absence of large tusks, a feature of most fully mature bull elephants in Sri Lanka. 
back of the ear with the animal in a standing position. The samples were heparinised, centrifuged at $3000 \mathrm{rpm}$ for $15 \mathrm{~min}$ within $60 \mathrm{~min}$, and the plasma samples were stored at $-20^{\circ} \mathrm{C}$. All serum and plasma samples were transported frozen from Sri Lanka to Edinburgh, UK for the measurement of testosterone concentrations by radioimmunoassay.

The behavioural characteristics of the elephants were assessed by the curator and mahouts, and recorded weekly. Individuals were classified as in musth when they showed at least two of the following features: enlarged temporal glands with continuous secretion; dripping urine; loss of appetite and restless behaviour; unusually aggressive behaviour to people or other animals. Detailed, twice monthly recordings of the interactions between adult elephants in the Pinnawala Orphanage were also made for 21 months from October 1986 (Poole et al., in press).

\section{Radioimmunoassays}

The concentrations of testosterone in the serum and plasma samples collected from the elephants were measured in duplicate by radioimmunoassay using the method of Corker and Davidson (1978), as modified by Sharp and Bartlett (1985) for iodinated tracer. The limit of detection of the assay was $0.1 \mathrm{ng}$ $\mathrm{ml}^{-1}$ and the intra- and interassay coefficients of variation (CV) were $6.8 \%$ and $10.0 \%$, respectively. The samples were assayed in batches covering periods of 14-20 months.

\section{Statistical analyses}

Changes in the blood concentrations of testosterone related to time of year were analysed for significance for individual elephants by analysis of variance (ANOVA) using data for four complete annual cycles. The correlation coefficient was calculated between mean concentrations of testosterone during the two months before onset of full musth and duration of musth using data for all animals showing musth. Significant peaks in the blood concentrations of testosterone in the profiles based on frequent sampling were defined as two consecutive values higher than the previous two values by twice the intra-assay $\mathrm{CV}$.

\section{Results}

\section{Testosterone profiles}

In all animals, there were marked variations in testosterone concentrations from week to week producing erratic profiles of testosterone concentrations (Figs 2 and 3). However, there were longer term changes with sustained periods of low and high concentrations of testosterone of variable duration (Fig. 4). This phasic pattern was most evident in the oldest animal (E11M, Fig. 2) which had mean concentrations of testosterone $<0.5 \mathrm{ng} \mathrm{ml}^{-1}$ for periods of $4-6$ months on three occasions during the 5 year study interrupted by periods of high concentrations with values ranging from 1-29 ng $\mathrm{ml}^{-1}$. In three of the six bulls, there was significant variation $(P<0.05)$ associated with time of year; the seasonal maximum

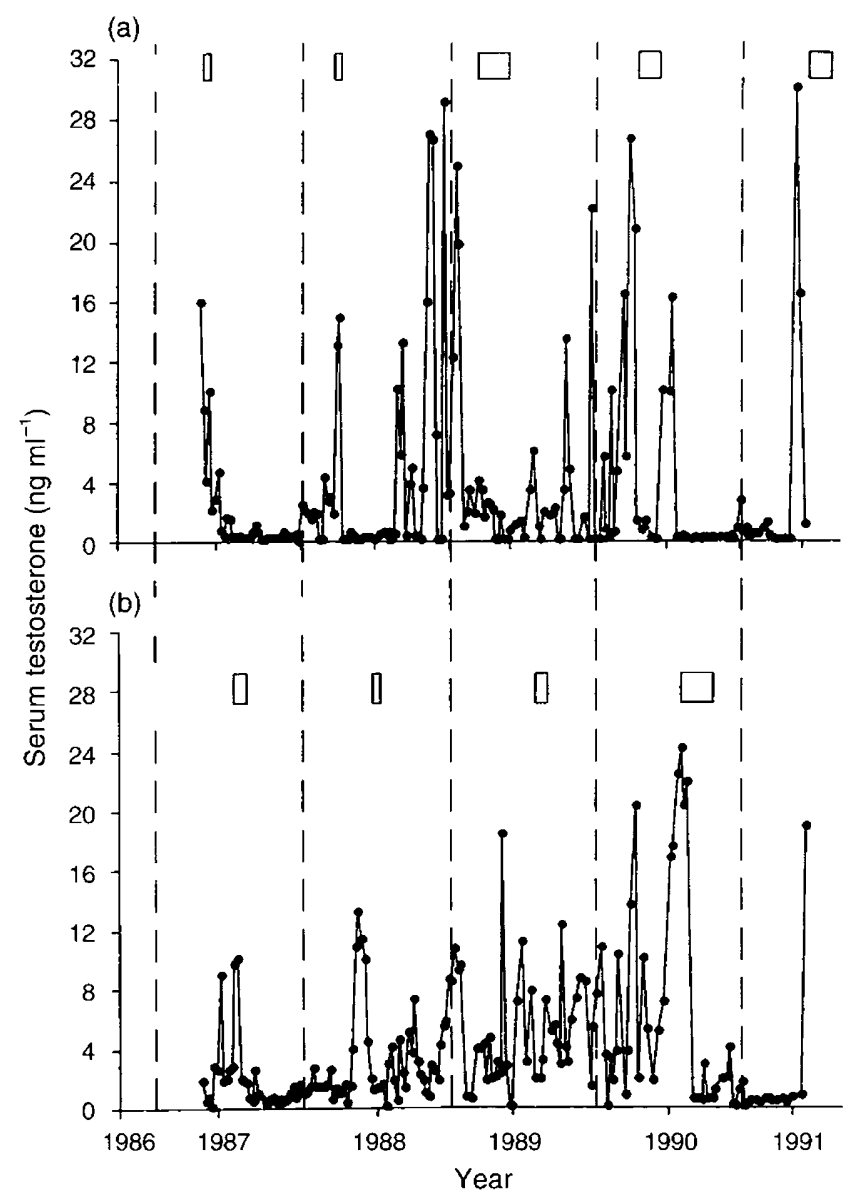

Fig. 2. Weekly changes in blood serum concentrations of testosterone and the occurrence of musth (open box) from 1986 to 1991 in two male elephants ((a) E11M and (b) E12M, 40 and 20 years old, respectively, in 1986) living in the National Zoological Gardens, Colombo, Sri Lanka.

occurred during November-March in E1TM, during May-July in E12M and in September-October in E3M (Fig. 4).

\section{Testosterone and behaviour}

The three bulls with the highest mean blood concentrations of testosterone (E11M, E12M and E3M) were generally more aggressive towards other elephants and showed periodic musth. The other bulls had lower testosterone concentrations and were non-cyclical (Figs 2 and 3). In the group living at the Orphanage, mean testosterone concentrations were positively correlated with social rank assessed during behavioural interactions while feeding and bathing (E3M, $2.60 \pm 0.36 \mathrm{ng} \mathrm{ml}^{-1}$; E6M, $2.33 \pm 0.25 \mathrm{ng} \mathrm{ml}^{-1}$; E4M, $1.13 \pm 0.23 \mathrm{ng} \mathrm{ml}^{-1}$; E5M, $0.70 \pm 0.13 \mathrm{ng} \mathrm{ml}^{-1}$, ranked $I$ to 4 respectively). Social rank remained stable throughout the study and play-fighting (Fig. 1) occurred most frequently between E3M and E6 $\mathrm{M}$ at the top of the hierarchy. In the animals which came into musth, the bouts of musth lasted from 2 to 10 weeks and occurred at a relatively consistent time of year for each animal (Figs 2-4). The musth periods were March-June for E11M, July-September for E12M and September-November for E3M. The first signs of musth 
(a)

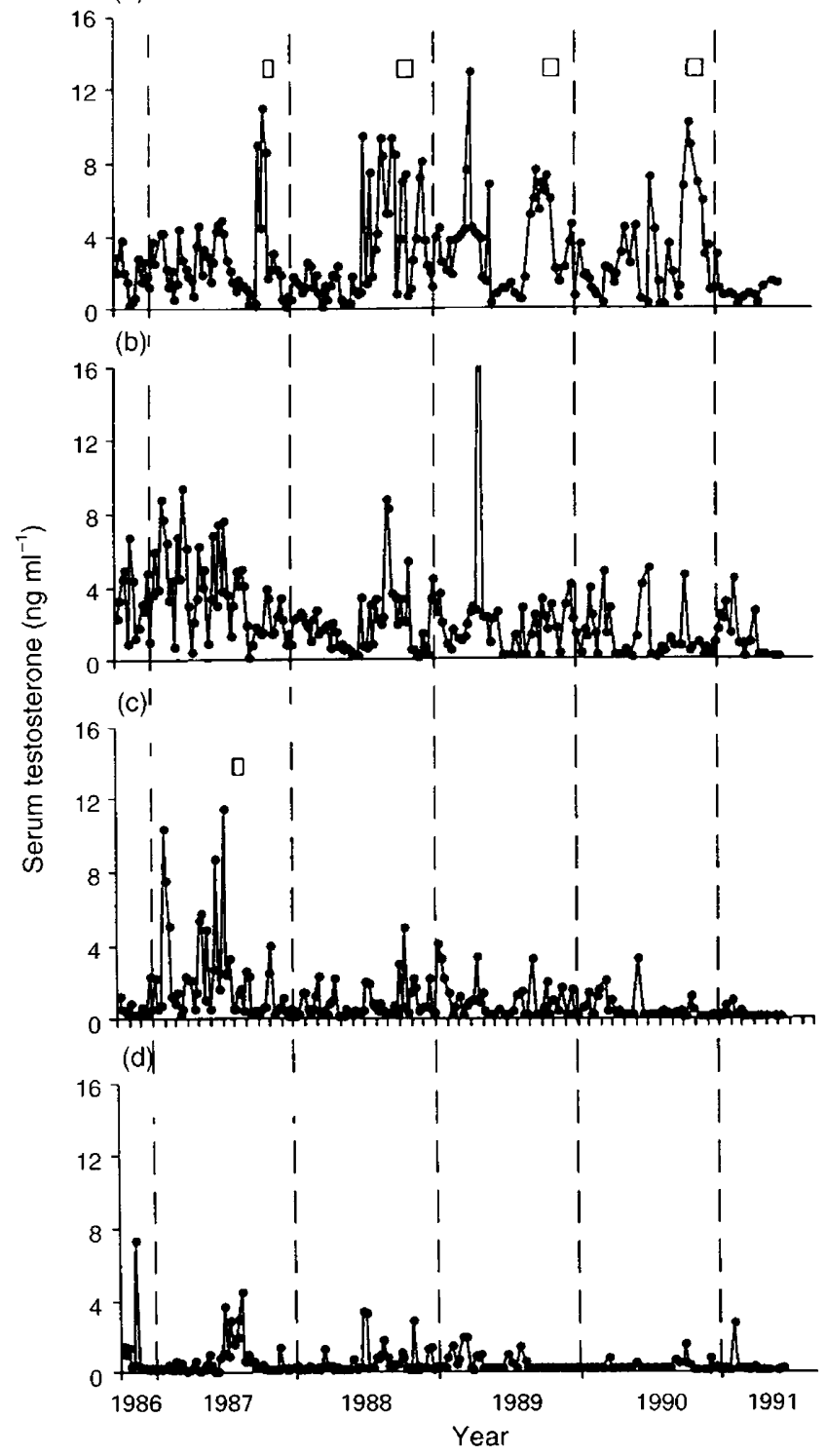

Fig. 3. Weekly changes in blood serum concentrations of testosterone and the occurrence of musth (open box) from 1986 to 1991 in four male elephants ((a) E3M, (b) E6M, (c) E4M and (d) E5M, 22, 20, 19 and 19 years old, respectively, in 1986) living in the Pinnawala Elephant Orphanage, near Colombo, Sri Lanka. The animals are listed in order of social dominance.

were initiated during, or shortly after, phases of high blood concentrations of testosterone, but the main bout of musth occurred when the testosterone concentrations were declining. There was a positive correlation between the mean concentration of testosterone in the 2 months before musth and the duration of musth $\left(r^{2}=0.92, P<0.001\right.$, data for three animals combined).

\section{Pulsatile secretion of testosterone and response to $\mathrm{GnRH}$}

The testosterone profiles based on blood samples collected every $15 \mathrm{~min}$ showed significant peaks in testosterone
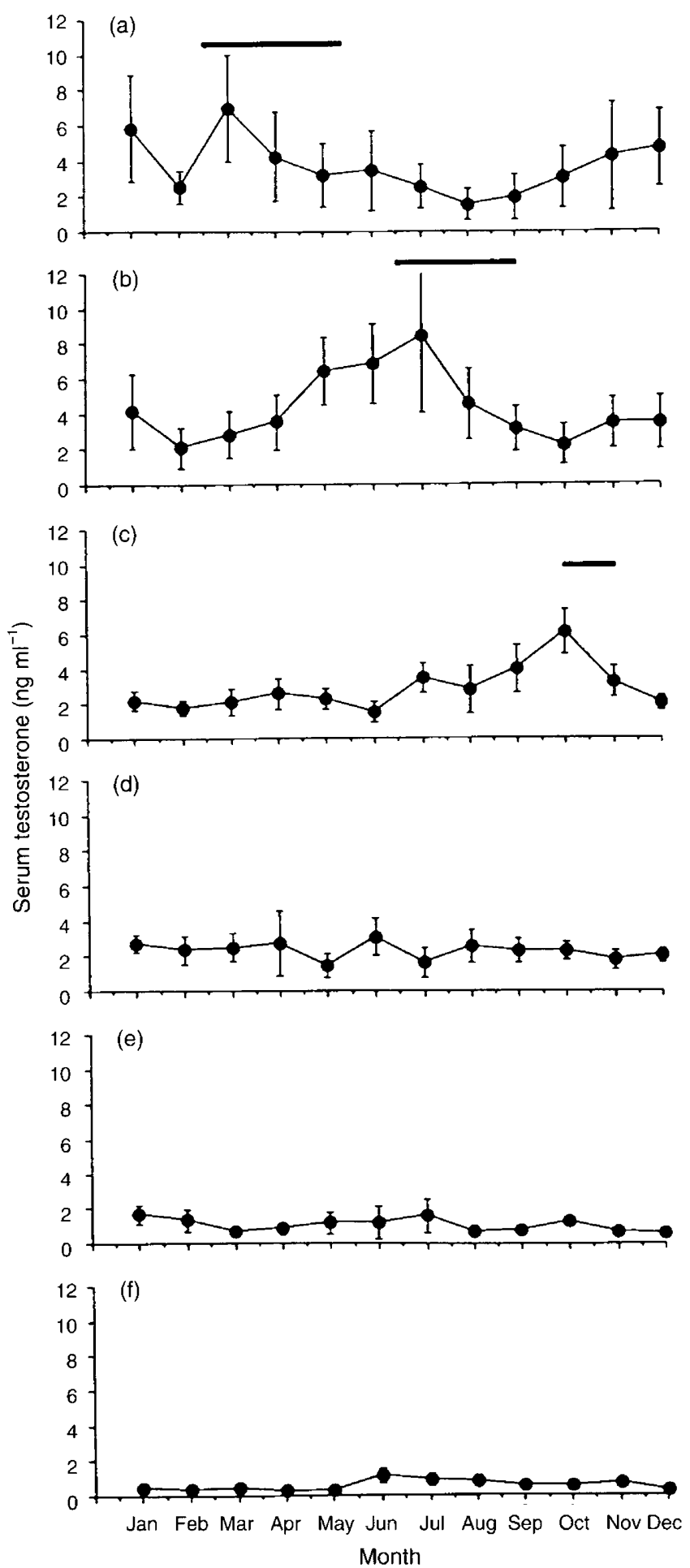

Fig. 4. Mean monthly changes in the blood serum concentrations of testosterone in six male elephants living in Sri Lanka ((a) EIIM, (b) E12M, (c) E3M, (d) E6M, (e) E4M and (f) E5M), based on blood samples collected weekly for 5 years. Values are means \pm SEM for the mean monthly value for the 5 years. The period of year during which musth occurred is indicated by the horizontal bar (earliest to latest dates in the 5 years).

concentrations during the $7 \mathrm{~h}$ sampling period, consistent with a low frequency, pulsatile pattern of secretion (Fig. 5). The 


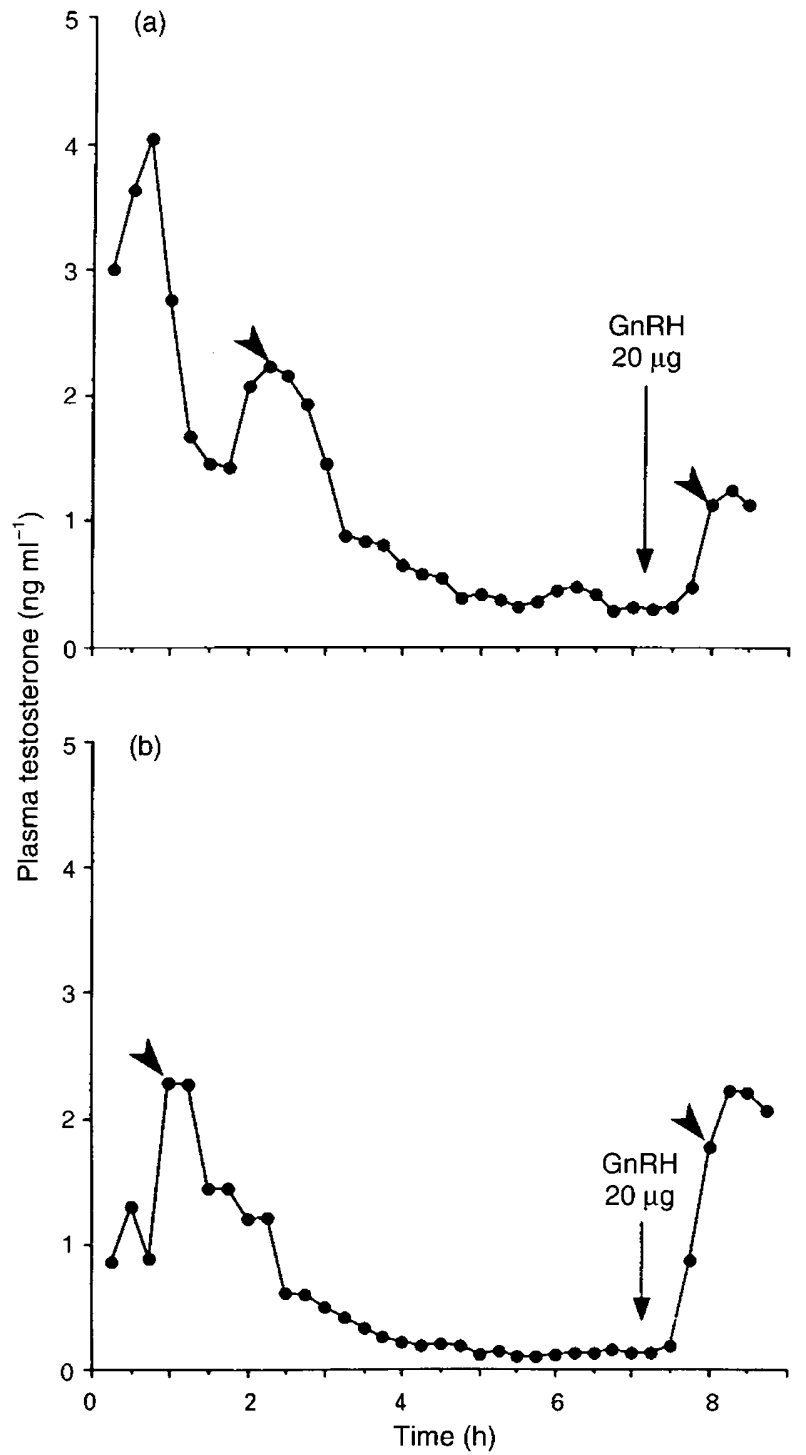

Fig. 5. Short-term fluctuations in the blood plasma concentrations of testosterone in two male elephants ((a) E6M and (b) E4M) living in the Pinnawala Elephant Orphanage, near Colombo, Sri Lanka. Blood samples were collected every $15 \mathrm{~min}$ for $7 \mathrm{~h}$ before and $2 \mathrm{~h}$ after an injection of GnRH in May 1991. Neither animal showed evidence of musth cycles during the 5 year study. The occurrence of significant peaks in the plasma concentrations of testosterone are indicated (arrowhead).

injection of $\mathrm{GnRH}(20 \mu \mathrm{g}$ per animal i.v.) induced an increase in testosterone concentrations in all six elephants with maximum concentrations after $45-60 \mathrm{~min}$ (Fig. 6). The largest response occurred in EIIM treated at the beginning of musth when basal testosterone concentrations were already very high.

\section{Discussion}

The serum testosterone profiles for the six male elephants in Sri Lanka were very variable both within and between animals and this tended to obscure the associations with musth and other characteristics. Week to week variability was predictable;

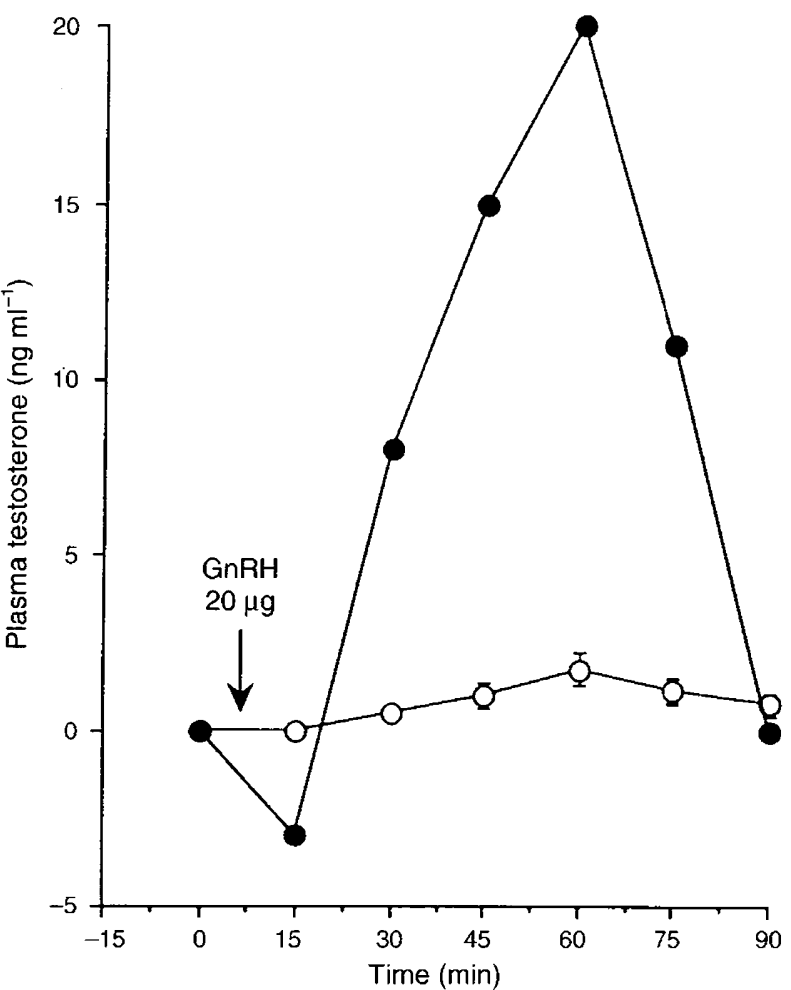

Fig. 6. Testosterone response to an injection of $\mathrm{GnRH}(20 \mu \mathrm{g}$ i.v.) in five of the male elephants not showing musth $(O$, mean $\pm \mathrm{SEM}, \mathrm{E} 3 \mathrm{M}$, E4M, E5M, E6M and E12M), and one male elephant in early musth (๑, EII) in May 1991.

however, since testosterone concentrations fluctuate in the short term due to the pulsatile pattern of LH secretion from the anterior pituitary gland (Niemuller and Liptrap et al., 1991), infrequent sampling provides only a random measure of this variation. The dynamic pattern of testosterone secretion was evident in the Sri Lankan elephants when blood samples were collected at frequent intervals. Furthermore, the injection of $\mathrm{GnRH}$ induced a transitory increase in the circulating concentrations of testosterone, which is consistent with the physiological regulation through the pulsatile secretion of $\mathrm{GnRH}$ governing $\mathrm{LH}$, and thus testosterone.

Long-term changes in serum concentrations of testosterone associated with periods of musth occurred in three of the elephants, and only the oldest animal showed a clearly defined phasic pattern. This lack of a robust reproductive cycle in most of the animals may reflect the relative immaturity of elephants; five of the bulls were 19-22 years old at the beginning of the observations. Asian elephants can live for more than 50 years increasing in body size throughout this time, and thus the elephants in the study were not fully mature, although they were in the age range normally classified as adults (adults $>22.5$ years: McKay, 1973; > 15 years: Daniel et al., 1987). Jainudeen et al. (1972b) observed that Asiatic elephants in India reached puberty at 3-5 years, but show little evidence of musth before 20 years of age, and bulls may be more than 30 years old before developing the circannual cyclical characteristic. In contrast to this situation, in male Asian elephants kept in captivity in northern climates outside the normal range for the species, males have been observed to show major and 
consistent annual changes in circulating testosterone concentrations with all the characteristics of musth when only 10-20 years of age (Rasmussen et al., 1984; Cooper et al., 1990; Niemuller et al., 1991). These differences indicate that seasonal changes in the environment may induce cyclical changes in the gonadal axis. The slower development, with a more erratic pattern of testosterone secretion as observed in Sri Lankan elephants, may illustrate the natural situation in the tropics.

The well established association between high testosterone secretion and musth was confirmed in the current study, although the maximum development of the various characteristics of musth occurred after, and not coincident with, maximum testosterone secretion as described, for example, by Niemuller et al. (1991). In the Sri Lankan bulls there was a positive correlation between the duration of musth and the mean testosterone titres over the previous 2 months. This finding indicates that the changes in testosterone may be causal in stimulating the onset of musth, but the intensity of musth is not simply related to testosterone titres. A more complex relationship between androgen secretion and the target organ responses has been noted for the association between circulating concentrations of testosterone and the activity of the temporal glands following food restriction (Cooper et al., 1990). In the Sri Lankan elephants the intensity of musth was often at a maximum many weeks after the peak in circulating androgen concentrations. This is similar to the situation described in male Soay sheep in which the aggression index (assessed from the interactions between neighbours) was maximal at least a month after the seasonal maximum in testosterone secretion, at a time when the androgen concentrations were rapidly declining (Lincoln and Davidson, 1977). In this species, males are overtly aggressive towards other males during the rut, but are readily provoked into showing aggression just after the rutting phase - termed the irritable male syndrome (Lincoln, 1986). In humans, a temporary reduction in testosterone concentrations in normal men can provoke increased aggressiveness, anger and irritability (Bagatell et al., 1994). On the basis of these observations, it is likely that the withdrawal of testosterone after a period of hypersecretion is the cause of some of the changes in behaviour associated with musth including aspects of aggression, unpredictability and disobedience which make male elephants so dangerous during musth.

The management of elephants in musth usually involves chaining the animals away from contact with people and other elephants, and the withdrawal of food to reduce the period of musth. Various traditional methods are also used including the mechanical stimulation of the 'nerve centre' in the anal fold (performed by the mahout with a metal ankus), and the provision of specific foods including rhyzomes of Bambusa vularus, aerial parts of Tetracera sarmentosa and leaves of Ficus tsielato (Ratnasooriya, 1990) which are thought to suppress musth. Since the behaviour is androgen dependent, the manipulation of the secretion or action of androgens is a logical way to control musth. Castration is not a practical option, however, since the testes in elephants are abdominal (Short et al., 1967), and castration would require relatively complex surgery. The anti-androgen cyproterone acetate has been given to bull Asian elephants at a dose of $2.5 \mathrm{mg} \mathrm{kg}^{-1}$, but it did not affect musth behaviour, or the timing of the musth cycle in subsequent years
(C. Niemuller, personal communication). GnRH analogues have been given to African elephants, and both antagonists and agonists had suppressive effects on the pituitary-testicular axis for up to 20 days (Brown et al., 1993). So far, however, there have been no long-term studies to develop practical methods to control the musth cycle using endocrine and pharmacological approaches. These treatments could involve implantation of GnRH superactive analogues, immunisation against GnRH or implantation with progestins which predictably would suppress gonadotrophin secretion for periods of more than a year and completely block the circannual musth cycle.

In conclusion, this study in Sri Lankan elephants describes for the first time the long-term testosterone profiles in elephants living near the equator. The variability indicates that the musth cycle is poorly expressed in young elephants under 25 years old, but becomes conspicuous with increasing age. Since musth occurred after periods of increased testosterone secretion, it is likely that high blood concentrations of testosterone cause the initiation of musth; however, the long latency indicates that the withdrawal of testosterone after a period of hypersecretion may provoke the negative behavioural traits such as unpredictable aggression, which is such a notable feature of musth.

The authors wish to thank S. B. U. Fernando, Director of the National Zoological Gardens, Colombo for permission to carry out the project, A. M. V. R. Manatunga and Staff of National Zoological Gardens for the hard work collecting the blood samples from the elephants, T. Poole of UFAW for organising the shipment of material to the UK, R. Cunningham and I. Cooper for expert technical assistance with the radioimmunoassays, and T. McFetters and T. Pinner for the art work. The project was supported by a grant from UFAW.

\section{References}

Bagatell CJ, Heiman JR, Rivier JE and Bremner WJ (1994) Effects of endogenous testosterone and estradiol on sexual behaviour in normal young men Journal of Clinical Endocrinology and Metabolism 78 711-716

Brown JL, Bush M, Wildt DE, Raath JR, de Vos V and Howard JG (1993) Effects of GnRH analogs on pituitary-testicular function in free-ranging African elephants (Loxodonta africana) Journal of Reproduction and Fertility $99627-634$

Cooper KA, Harder JD, Clawson DH, Frederick DL, Lodge GA, Peachey HC, Spellmire TJ and Winstel DP (1990) Serum testosterone and musth in captive male African and Asian elephants Zoo Biology 9 297-306

Corker CS and Davidson DW (1978) The radioimmunoassay of testosterone in various biological fluids without chromatography Steroid Biochemistry 9 373-374

Daniel AA, Sivaganeson N and Kumar SR (1987) Study of the ecology of some endangered species of wildlife and their habitats - the Asian elephant Bombay National History Society Report October 1985-1987

Eisenberg JF, McKay GM and Jainudeen MR (1971) Reproductive behaviour of the Asiatic elephant (Elaphas maximus L) Behaviour 38 193-217

Hall-Martin AJ (1987) Role of musth in the reproductive strategy of the African elephant (Loxodonta africana) South African Journal Science $\mathbf{8 3}$ 616-620

Hall-Martin AJ and van der Walt LA (1984) Plasma testosterone levels in relation to musth in the male African elephant Koedoe 27 147-149

Jainudeen MR, Katongole CB and Short RV (1972a) Plasma testosterone levels in relation to musth and sexual activity in the male Asian elephant (Elaphas maximus) Journal of Reproduction and Fertility 29 99-103

Jainudeen MR, McKay GM and Eisenberg JF (1972b) Observations on musth in the domesticated Asiatic elephant (Elaphas maximus) Mammalia 36 247-261

Lincoln GA (1986) Seasonal aspects of testicular function. In The Testis (2nd Edn) pp 329-385 Eds H Burger and D de Kretser. Raven Press, New York 
Lincoln GA and Davidson $W$ (1977) The relationship between sexual and aggressive behaviour, and pituitary and testicular activity during the seasonal sexual cycle in rams, and the influence of photoperiod Journal of Reproduction and Fertility 49 267-276

McCaughley CA (1963) Musth Ceylon Veterinary Journal 11 105-107

McKay GM (1973) Behaviour and ecology of the Asian elephant in South Eastern Ceylon Smithsonian Contribution to Zoology 125 1-113

Niemuller CA and Liptrap RM (1991) Altered androstenedione to testosterone ratios and $\mathrm{LH}$ concentrations during musth in the captive male Asian elephant (Elephas maximus) Journal of Reproduction and Fertility 91 139-146

Poole JH (1987) Rutting behaviour in African elephants: the phenomenon of musth Behaviour 102 282-316

Poole JH (1989) Mate guarding, reproductive success and female choice in African elephants Animal Behaviour $37842-849$

Poole JH (1994) Sex differences in the behaviour of African elephants. In The Differences between the Sexes pp 331-346 Eds RV Short and E Balaban. Cambridge University Press, Cambridge
Poole JH and Moss CJ (1981) Musth in the African elephant (Loxodonta africana) Nature $292830-831$

Poole TB, Taylor VI, Fernando SBU, Ratnasooriya WD, Ratnayeke A, Lincoln GA, McNeilly AS and Manatunga AMVR Social behaviour and breeding physiology of a group of captive Asian elephants International Zoo Yearbook (in press)

Rasmussen LE, Buss IO, Hess DL and Schmidt MJ (1984) Testosterone and dehydrotestosterone concentrations in elephant serum and temporal gland secretions Biology of Reproduction 30 352-362

Ratnasooriya WD (1990) Vanishing elephant Proceedings of the 46th Annual Sessions of the Sri Lankan Association for the Advancement of Science pp 47-58 Colombo Sri Lanka

Sharpe RM and Bartlett JMS (1985) Intratesticular distribution of testosterone in rats and the relationship to the concentration of a peptide that stimulates testosterone secretion Journal of Reproduction and Fertility 73 223-236

Short RV, Mann T and Hay MF (1967) Male reproductive organs of the African elephant (Loxodonta africana) Journal of Reproduction and Fertility 13 517-536 